\title{
Performance and Prospects of Severe Plastic Deformation for Effective Biomedical Titanium Alloys
}

\author{
Wambura Mwiryenyi Mwita*, Esther Titilayo Akinlabi, Kazeem Oladele Sanusi \\ Department of Mechanical Engineering Science, Faculty of Engineering and the Built Environment, \\ University of Johannesburg, PO BOX 524, APK 2006, Republic of South Africa \\ * Corresponding author email: mwita_wa@yahoo.com
}

Received: 30 December 2017 / Revised: 19 February 2018 / Accepted: 22 February 2018 / Published: 26 February 2018

\begin{abstract}
Application of severe plastic deformation (SPD) technology to process effective biomedical titanium alloys has shown promising results at laboratory scale. However, more research is still required before adopting this technology from laboratory scale to industrial scale production. This review presents performance and prospects of SPD for effective ultra-fine/nanograin structure-biomedical titanium alloys. Effective biomedical titanium alloys should have desired properties for the medical application. The properties include; high static and fatigue strengths, surface hardness for wear resistance, good ductility, corrosion resistance and biocompatibility. Based on current works reported in the literature, the review focused on; high-pressure torsion (HPT), equal channel angular pressing (ECAP), asymmetric rolling (AR), accumulative roll bonding (ARB) and repetitive corrugation and straightening (RCS). Overview of biomedical application of titanium alloys and desired material properties is presented. A detail discussion on the working principle, performance (e.g. induced strength, hardness, grain size and texture etc.) and material deformation homogeneity of each SPD method are presented. Also, prospects and challenges of each SPD method to be implemented at industrial scale for continuous and mass production are highlighted. The review concludes with the effectiveness of SPD processes, characteristics of processed samples and suggestion of future work for SPD to process effective biomedical titanium alloys at industrial scale.
\end{abstract}

Keywords: Accumulative roll bonding, asymmetric rolling, biocompatibility, biomedical alloy, equal channel angle pressing, high pressure torsion, repetitive corrugation and straightening, severe plastic deformation, strain homogeneity.

\section{Introduction}

Biomedical alloys are alloy materials used for medical purposes. They are used for making prostheses (artificial organs), body implants, surgical tools and other related medical equipment. These alloys are preferred to have; high static and fatigue tensile strength, sufficient ductility and low Young's Modulus (stiffness) close to that of the human bone. Other desirable properties are; excellent corrosion and wear resistance, nontoxicity, good biocompatibility of the material with the host body when tested in vivo and vitro environment [1][2][3][4]. Examples of biomedical alloys are titanium alloys, stainless (S-S) steels and cobalt chromium (Co-Cr) steels[5][6].

Titanium and its alloys have got a wide biomedical application; these alloys are preferred to (S-S) steels and (Co-Cr) steels based on their low stiffness with high strength to weight ratio, non-magnetic and good biocompatibility. In addition to poor corrosion resistance, excessive high elastic moduli of S-S and $\mathrm{Co}-\mathrm{Cr}$ steels (relative to that of the bone) results to high stress shielding along body-implant interfaces. Also Co$\mathrm{Cr}$ releases $\mathrm{Co}$ and $\mathrm{Cr}$ allergic ions that may be harmful to the host body [7][8]. Titanium alloys have relatively higher corrosion resistance than other biomaterials, for instance the stable and 
strong titanium oxide $\left(\mathrm{TiO}_{2}\right)$ can form on the surface of pure titanium and grows spontaneously in contact with air. The oxide prevents the diffusion of the oxygen from the environment to material, hence enhances the material with high corrosion resistance. Titanium and its alloys are used for making medical body implants and prostheses for orthopaedic, dentistry, vascular, cardinal and neurology [7][9][10]. Commercially pure titanium (CP-Ti) is in a group of $\alpha$-titanium with densely hexagonal close packed (hcp) crystal structure. CP-Ti is further classified into four grades ie G1, G2, G3 and G4 based on oxygen and iron composition. The average Young's Modulus of $\alpha$-titanium is $100 \mathrm{GPa}$. CP-Ti alloys currently remain low stiffness and best nontoxic materials for bio implants. However, their main drawbacks are low strength and poor wear resistance that may lead to implant failure under various operating forces [11]. Therefore CP-Ti is limited to low strength application such as making orthodontic guide wires and dental screws [2][12]. Titanium alloys with $\mathrm{Nb}, \mathrm{Ta}, \mathrm{Zr}, \mathrm{Cr}$, Mo elements (examples Ti29Nb-13Ta-4.6Zr, Ti-13Nb-13Zr, Ti-15Mo) are $\beta$-titanium with less densely body centered cubic (bcc) crystal structure. These alloys have low Young's Modulus ranging from 55-100 GPa. The $\beta$-titanium alloys are also nontoxic and are preferred for body implant due to their lower stiffness than CP-Ti. However, they also exhibit low strength that may lead to implant failure under static and dynamic forces [4][5].

Another wide used biomedical titanium alloy is Ti-6Al-4V (mainly composed of titanium, aluminium and vanadium). It is in a group of $\alpha+\beta$-titanium with a Young's Modulus ranging from 100-110 GPa [4]. Ti-6Al-4V has higher strength and wear resistance than CP-Ti, it has been used for biomedical implants such as orthopaedic guide plates, surgical tools and stents. However, this alloy has shown serious adverse allergic effects to the host body. In addition to high stress shielding, it releases toxic $\mathrm{Al}$ and $\mathrm{V}$ ions to the body cells and tissues [6], [13], [14]. Titanium shape memory alloys such as Ti-22Nb-6Ta and Ni-Ti (popularly known as nitinol) are titanium alloys that exhibit two unique properties namely shape memory (SM) and super-elasticity (SE) [15]. In SM, the material is capable of recovering a large residual strain (up to $6 \%$ via martensite-austenite phase transformation when heated to the austenite finish temperature. In SE, the material when loaded at austenite finish temperature may deform beyond elastic strain, but it recovers the strain completely via stress induced martensiteaustenite phase transformation upon removal of the load. Very high compressive stresses in material are accompanied by SM and SE phenomena. This has made these alloys suitable for spinal discs stabilization, fractured bones joining, artificial valves and muscles [13][14].

In the last three decades, the use of SPD to process ultrafine/nano titanium alloys with enhanced properties for biomedical application has drawn attention of many researchers. Various works reported in the literature have proved ability of SPD techniques to enhance titanium alloys with ultra-fine/nano grain structure, improved properties such as tensile strength, induced strain, hardness, wear, corrosion resistance and biocompatibility [1], [12], [16][20]. So far reported SPD achievements are at experimental stage, yet they have not been implemented at industrial scale. The purpose of this review is to investigate performance and challenges of SPD to process effective titanium alloys for biomedical application. Performance parameters investigated include; grain refinement and texture, magnitude and homogeneity of induced strength and strain. The review identifies the prospects of adaptation of each SPD technology from laboratory scale to the industrial scale, also potential areas that need more research are proposed for SPD to process effective biomedical titanium alloys at industrial continuous and mass production scale. The focus of this review was on HPT, ECAP, AR ARB and RCS SPD processes whose detail discussions are given in chapter two.

\section{Severe Plastic Deformation (SPD) Methods for Effective Biomedical Titanium Alloys}

Ideally, an SPD involves subjecting the material to a high hydrostatic (three dimensional) stress state that creates plastic deformation of material 
sample in form of pure or simple shear without significantly changing its overall dimensions. The SPD basic principle is illustrated in Figure 1, where a solid body is hydrostatically loaded. In practical, SPD can be induced in material by stress loads in form of tension, compression, bending, torsion or a combination of them.

Load

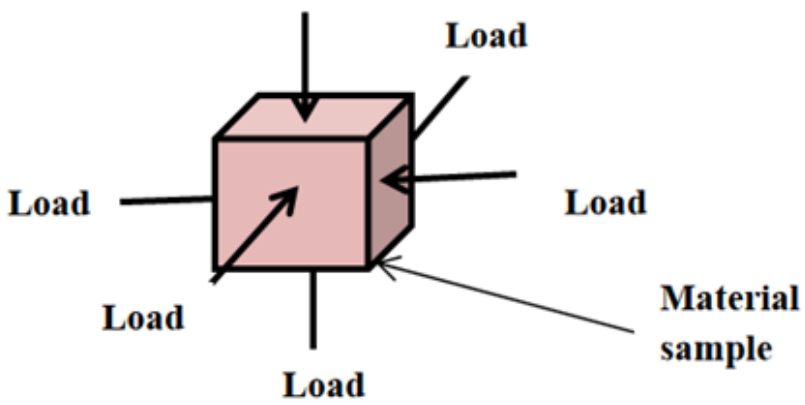

Figure 1: Hydrostatically loaded $3 D$ body with compressive load represented by arrows.

In SPD, accumulation of plastic deformation/strain increases number of crystal lattice dislocations whose movements are pinned. Pinned dislocations result to increase of grain boundaries with rearrangement of coarse grains into fine grains. The grain size achieved can be in the range of ultra-fine scale $(100 \mathrm{~nm}=$ grain size $<1000 \mathrm{~nm}$ ) or nano scale (grain size $<100 \mathrm{~nm}$ )[16][21]. The Hall-Petch grain boundary strengthening and Hollomon's work hardening theories are used to quantify the relationship between severe plastic deformation of material, its transformation from coarse grain to ultra-fine/nano grain structure and resulting strength properties [22]. The Hall-Petch equation predicts the relation between yield strength and average grain size of material as:

$s_{y}=S_{0}+\frac{K}{\sqrt{D}}$

$\mathrm{S}_{\mathrm{y}}=$ yield stress, $\mathrm{S}_{\mathrm{o}}=$ material constant for starting stress for dislocation movement, $\mathrm{K}=$ material dependent strengthening coefficient and $\mathrm{D}=$ average grain diameter. The Hollomon's equation is a power law relation between stress and the amount of induced plastic strain given as:

$S=H \varepsilon_{p}^{n}$

$\mathrm{S}=$ stress, $\mathrm{H}=$ strength coefficient, $\varepsilon_{\mathrm{p}}=$ induced plastic strain and $\mathrm{n}=$ strain hardening coefficient material property. Ludwik's equation is the power law equation that includes the yield strength $\left(\mathrm{S}_{\mathrm{y}}\right)$ and considers plastic strain $\left(\varepsilon_{0}\right)$ due to prior deformation of material. It is written as:

$$
S=S_{y}+H\left(\varepsilon_{o}+\varepsilon_{p}\right)^{n}
$$

The capability of the SPD processes to refine grain structure and texture of materials has made them efficient advanced manufacturing processes for titanium alloys and other materials with enhanced properties such as improved strength, hardness and wear resistance [23][24]. Benefits of the SPD processes include; Economic of raw materials-most SPD processes can change material properties such as strength and grain refinement without significant addition of other raw materials. Manufacturing compatibility-a series of SPD processes can be performed on material to achieve better properties. Environmental friendly processes-SPD processes are clean manufacturing since the processes are not associated with release of harmful gases and chemicals that may cause environmental pollution. Among most successful ultra-fine and nano grain structuring SPD processes are; high pressure torsion (HPT), equal channel angle pressing (ECAP), accumulative roll bonding (ARB), asymmetric rolling (AR) and repetitive corrugation and straightening (RCS) [25][26]. Traditional deformation techniques such as conventional rolling, drawing and forging can also induce plastic shear strain in materials. However, the work pieces processed by these methods are associated with significant changes in geometric dimensions.

\subsection{High Pressure Torsion (HPT)}

HPT is the SPD process where material sample is held between an upper and lower anvils and one of them rotates under high compressive pressures (in a range of 1-10 Giga Pascal) [17]. The working principle of HPT is represented in Figure 2, the process is a true hydrostatic stress state as material sample is subjected simultaneously to compression and twisting loads while maintaining its geometric dimensions. 


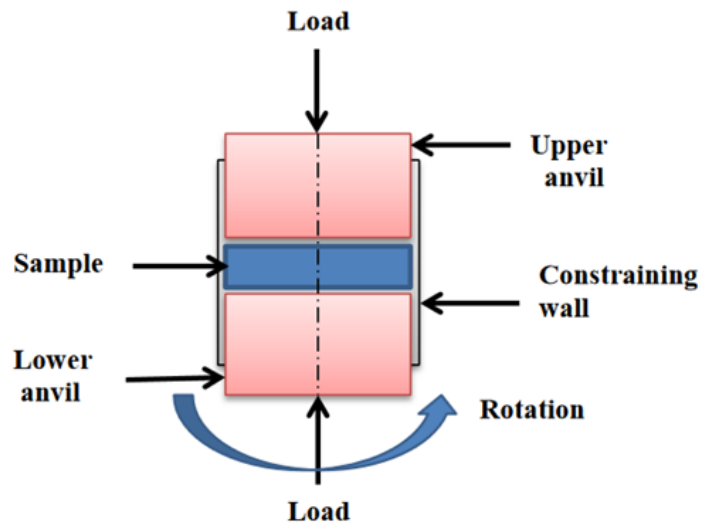

Figure 2: Principle of HPT process

The mode of plastic deformation is pure shear due to surface friction forces. The effective strain induced in deformed cylindrical material sample under HPT is given by equation (4) [22] as:

$\mathcal{E}_{\text {eff }}=N \frac{2}{\sqrt{3}} \frac{\pi r}{t}$

$\mathrm{r}=$ distance from the sample axis, $\mathrm{t}=$ thickness of sample and $\mathrm{N}=$ number of

passes (complete rotations). The induced strain is directly proportional to the radius $r$, from the center axis and the number of passes, $\mathrm{N}$ and is inversely proportion to the thickness, $t$ of the sample. Regardless to the number of passes performed, this mathematical relation implies that the strain induced in the sample decreases from its outer circle, $r$ towards the center, also strain decreases with the increase of the sample thickness, t. This results to deformation heterogeneity and limitation of the size of the processed samples. These have been major challenges of HPT. Other factors such as magnitude of plastic strain induced, magnitude of applied pressure and torque, contact surfaces friction and the working temperature have influence on the performance of this process [27][28]. Various works in the literature have proven that HPT is currently the most effective SPD method for ultra-fine/ nano grain biomedical titanium alloys with improved mechanical properties [29][30][31]. The use of HPT on biomedical titanium alloys has achieved ultra-fine/nano grain titanium with the ultimate tensile strengths of $10 \%-100 \%$ over that of the coarse grain one. For instance, the following authors reported on percentage increase of tensile strength of biomedical titanium alloys processed by HPT; Ashida et al. [32] on Ti-6Al$7 \mathrm{Nb}(19 \%)$, Jiang et al. [33] on Ti-5Al-5Mo-5V$3 \mathrm{C}(14.6 \%)$ and Sharman et al. [34] on Ti-24Nb$4 \mathrm{Zr}-8 \mathrm{Sn}(50 \%)$.

Nie et al. [35] worked on corrosion behavior of CP-Ti processed by HPT at $6 \mathrm{GPa}, 10$ passes. Results showed that, there was a decrease of grain size from $10 \mu \mathrm{m}-110 \mathrm{~nm}$ with increased dislocation density. Corrosion resistance of ultragrain material was lower than that of coarse grain material. The hardness of tested samples increased from 182HV-319HV. There was hardness heterogeneity in material but decreased with increase of deformation passes. Wang et al. [23] worked on effect of grain size on tribological behavior of CP-Ti formed by HPT, results showed that fine grain material showed better wear resistance than course grain one. A grain size of $607 \mathrm{~nm}$ was achieved, course gained CP-Ti showed plastic wear while ultra-fine grain ones had abrasive wear. On his other work [36] on hardness homogeneity and grain refinement of HPT processed CP-Ti, results showed that mean grain size of $105 \mathrm{~nm}$ at 6GPa pressure and 20 passes was achieved. Hardness heterogeneity in the test samples was observed. The hardness homogeneity improved with the increase of HPT turns.

Shahmir et al. [24] worked on microstructure and hardening of $\mathrm{Ni}-50.2 \mathrm{Ti}$ and $\mathrm{Ni}-50 \mathrm{Ti}$ shape memory alloys processed by HPT at $2 \mathrm{GPa}, 40$ passes. Results showed that both alloys exhibited martensite-austenite phase transformation with a reduced phase transformation temperature. Maximum hardness achieved in samples was 632 $\mathrm{HV}$ and $623 \mathrm{HV}$ for $\mathrm{Ni}-50.2 \mathrm{Ti}$ and Ni-50Ti respectively. The critical austenite grain size was $250 \mathrm{~nm}$. On his other work [37] on performing HPT on Ni-Ti followed by post deformation annealing showed improved shape memory effect, increase of recovery strain by $40 \%$, stabilized phase and the critical austenite grain size of $150 \mathrm{~nm}$. Both of above cases showed hardness heterogeneity in the samples by more than $50 \%$ between center and outer surfaces with increased dislocation density and high angle grain boundaries texture. 
Attempts have been made to improve HPT into a continuous process and capable to process workpieces of larger sizes. Edalati et al. [30] used continuous high pressure torsion (C-HPT) method to process copper and aluminium wires. The diameter and length of the samples were $2 \mathrm{~mm}$ and $100 \mathrm{~mm}$ respectively. Results showed that the time to process a specimen for one turn was 1 minute. Aluminium reached the steady state level with grain size of $1.3 \mu \mathrm{m}$ but copper had microstructure in non-steady state with grain size in the range of $0.3-4 \mu \mathrm{m}$, this was due to insufficient strain imposed in copper. Hohenwarter [38] used incremental high pressure torsion (I-HPT) to process ultrafine copper cylindrical samples of larger sizes $(50 \mathrm{~mm}$ diameter and height $70 \mathrm{~mm}$ ) than conventional sizes $(20 \mathrm{~mm}$ diameter and height $10 \mathrm{~mm})$. Both radial and axial deformation and hardness heterogeneities were observed in the samples due to the increased dimensions (height and radius). To make a conclusion, HPT is the most effective SPD method for producing ultrafine/nano biomedical titanium alloys with enhanced desired properties without significantly changing the sample dimension. This is due to its competing true hydrostatic stress state that imposes effective shear strain with low possibility of material cracking. However, HPT is limited to small sample sizes, processed samples exhibit a high level of strain heterogeneity and reduced ductility. More research needs to be done to improve this process to be capable for continuous processmass production, produce samples of large size and variable geometries with improved ductility, microstructure and strain homogeneity.

\subsection{Equal Channel Angle Pressing (ECAP)}

ECAP process involves repeated inserting of a billet (sample) in a die, which contains two channels with equal cross section intersecting at an angle $\phi$. The working principle of ECAP process is represented in Figure 3. The intersecting angle $\phi$ ranges from $90^{\circ}$ to $157.5^{\circ}$ [25] [39]. The process is a true hydrostatic stress state as material is deformed severely in a simple shear as it is pressed and changes its direction through the die section.

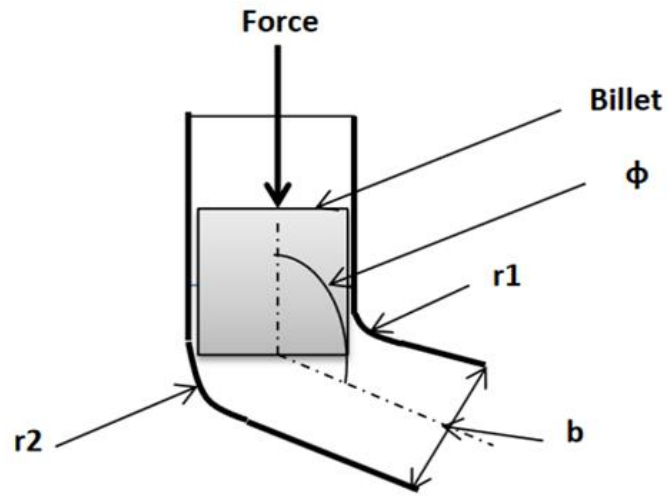

Figure 3: Principle of ECAP process

The effective strain induced in deformed material sample under ECAP is given by equation (5) [22] as:

$\varepsilon_{\text {eff }}=N \frac{2}{\sqrt{3}} \operatorname{Cot} \frac{\Phi}{2}$

$\Phi=$ Included die axes angle, $\mathrm{N}=$ number of passes. The induced shear strain is dependent on the number of passes $\mathrm{N}$ and the die included angle $\phi$. Other die geometric parameters are inner radius $r 1$, outer radius $r 2$ and die width $b$. Induced shear strain is also affected by non-geometric factors such as; magnitude of applied pressing load, contact friction between the billet and die surface and working temperature [40][41][42]. The shear strain heterogeneity in ECAP processed billets is mainly contributed by two factors; firstly, the difference of material flow velocities along the inner and outer radii of the die. Secondly is abrupt change of stress state from compression hydrostatic stress state to tension hydrostatic stress state as the material enters and leaves the shear (deformation) plane respectively. This can even cause cracking of the billet[8][26]. Various works on application of ECAP to improve desired properties of biomedical titanium alloys have been reported in the literature [19][43]. Gu et al. [41] investigated deformation behavior and mechanical properties of CP-Ti grade- 2 under Rotary Die-ECAP at 4 passes and $420^{\circ} \mathrm{C}$ temperature. Results showed that processed samples exhibited twining deformation on 1 and 2 passes and slip deformation on 3 and 4 passes. Samples had decreased grain size from $10 \mu \mathrm{m}-500 \mathrm{~nm}$. The 
Performance and Prospects of Severe Plastic Deformation for Effective Biomedical Titanium Alloys

tensile strength increased by $39 \%$ from $470 \mathrm{MPa}$ and elongation to fracture decreased from $58 \%$ 29\%. Prokofyev et al. [44] worked on microstructure, mechanical and functional properties of NiTi alloy processed by ECAP technique. Results showed that an ultra-fine grain size up to $200 \mathrm{~nm}$ was achieved on material sample diameters of $16 \mathrm{~mm}-20 \mathrm{~mm}$. Also, the yield strength improved up to $1300 \mathrm{MPa}$ and maximum recovery stress and strain were 1100 $\mathrm{MPa}$ and $9.2 \%$ respectively.

Zang et al. [45] worked on effect of annealing temperature on martensite phase transformation of NiTi alloy processed by ECAE. During cooling, material showed $\mathrm{B} 2 \rightarrow \mathrm{R} \rightarrow \mathrm{B} 19^{\prime}$ two stage phase transformation. At annealing temperature less than $400^{\circ} \mathrm{C}$, heating material showed $\mathrm{B} 199^{\prime} \rightarrow \mathrm{R} \rightarrow \mathrm{B} 2$ two stage phase transformation, the transformation temperature increased with annealing temperature. At annealing temperature higher than $500^{\circ} \mathrm{C}$, heating material showed $\quad \mathrm{B}^{\prime} 9^{\prime} \rightarrow \mathrm{B} 2$ single stage phase transformation while transformation temperature decreased with annealing temperature. The work done by Kockar et al.[46] has also shown that ECAP processed NiTi SMA has lower transformation temperatures and better cycling stability. Shahmir et al. [47] showed that shape memory effect and hysteresis loop of NiTi processed by ECAP at room temperature was improved by post deformation annealing (PDA) on the material at $500^{\circ} \mathrm{C}$ for 5-300 minutes.

Experimental based works to improve ECAP to a continuous process for large size samples have been reported. Qarni et al. [48] used IncrementalECAP to process CP-Ti at 6 passes. Results showed achievement of $89 \mathrm{~nm}$ from $22 \mu \mathrm{m}$ grain size with a continuous dynamic recrystallization (CDR) grain refinement mechanism. There were increase of $81 \%$ and $25 \%$ of yield and ultimate strength respectively, 38\% homogeneous hardness. Gzyl et al. [43] worked on IncrementalECAP process to process long billets of various dimensions including bars, plates and sheets. ECAP-Conform process was introduced to improve the ECAP to a continuous production process for long billets, Polyakov et al. [1] experimented on fatigue properties of $\mathrm{CP}-\mathrm{Ti}$ grade 4 processed by combined 8 passes-ECAP-
Conform then Drawing-85\% thickness reduction processes. The diameter and maximum length of processed samples were $6 \mathrm{~mm}$ and $2 \mathrm{~m}$ respectively. Fatigue strength of material increased from $320 \mathrm{MPa}$ to $620 \mathrm{MPa}$ while ductility decreased from $21 \%$ to $10 \%$. The grain size decreased from $25 \mu \mathrm{m}-200 \mathrm{~nm}$. The ECAP-C deformed samples showed improved osseointegration-biocompatibility than original samples. Other works have been reported in the literature on a series combination of ECAP process with other SPD methods to enhance better biomedical titanium material properties. Mendes et al. [49] studied microstructure and strength of CP-Ti grade2 under combined processes of warm ECAP at 4 passes, $300^{\circ} \mathrm{C}$ then cold rolling (CR) at $70 \%$ reduction thickness. Results showed an increase of; tensile strength (from 408-796MPa), hardness (from 140$271 \mathrm{HV}$ ) compared to annealed condition. $80 \%$ of strength was due to warm ECAP. There were equiaxed, elongated grains of size $100 \mathrm{~nm}$. The warm ECAP processed samples had higher ductility of $25 \%$ compared to $12 \%$ of samples ECAP deformed at room temperature. The ECAP process is effective to process ultrafine/nano biomedical titanium with desired properties without significantly changing the sample geometric dimension. However, this process is associated with heterogeneity shear strain distribution and loss of ductility of processed material at room temperature. It needs massive forces to press the workpiece through the die due to workpiece-die wall contact friction forces generated. Mostly it has been applied discontinuously on small size samples. It has not been implemented for mass production of large specimens of different geometries. More research is required to improve efficiency of the process, the effect of factors such as lubrication, die geometry and deformation rate on resulting material properties need to be investigated. Researchers have to develop improved technologies for ECAP pressing dies that can accommodate samples of various geometries and sizes. 
Mwita et al., J. Mod. Mater;; Vol. 5, Issue 1, pp: 8-23, 2018

\subsection{Asymmetric Rolling (AR)}

Asymmetric rolling is an SPD process where material samples in form of sheets or foils are rolled with a pair of rollers with different rotational speeds where the top roller rotates faster than the bottom roller. The working principles of AR and Symmetric Rolling (SR) are presented in Figure 4. The asymmetry can be introduced to the rolling process by using a pair of; either rollers of unequal diameters, or rollers of different friction properties materials (that will impose different friction forces on upper and lower surface of a deformed sample), or rollers of different rotational speed [50]. According to Roumina and Sinclair [51], unequal velocities imposed on the top and bottom of the surfaces of the sample results to shifting of neutral points (the points where the sheet velocity equals the roll velocity) on upper and lower surfaces of the sample. a)

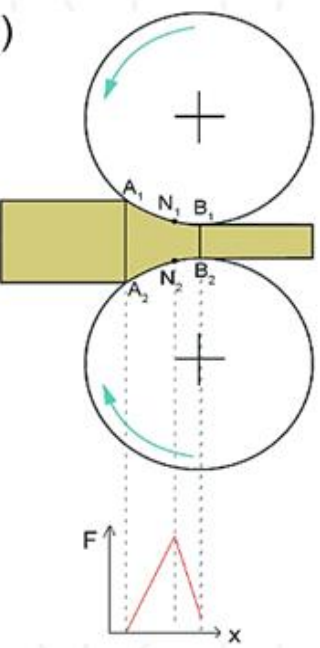

b)

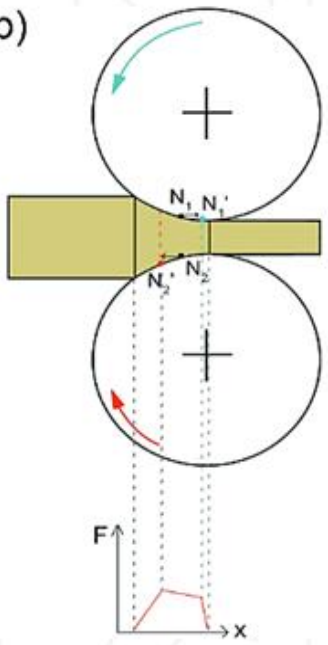

Figure 4: A rolling gap geometry in: (a) Symmetric rolling (SR)-equal roller velocities and neutral points $N_{1}, N_{2}$ (b) Asymmetric rolling (AR)-unequal roller velocities and shifted neutral points, $N_{1}{ }^{\prime}, N_{2}{ }^{\prime}$. Note: The rolling force $(F)$ in SR is higher than that of AR [50].

In Figure 4 (b), assuming the top roller has higher velocity than bottom roller, the neutral point of the bottom roll is shifted toward the entrance of the roll gap, while the neutral point of the top roll is moved toward the exit of the roll gap. This situation results to imposition of high shear strain and variation of rolling pressure distribution across the sample. Unequal distribution of rolling pressure has an advantage of reduced rolling force and torque. Effective strain induced in AR deformed material sample is given by equation (6) [52] as:

$\varepsilon_{\text {eff }}=N \frac{2}{\sqrt{3}} \sqrt{1+\left[\frac{(1-r)^{2}}{\left(2 r-r^{2}\right)} \tan \theta\right]^{2}} \ln \frac{1}{1-r}$

$r=1-\frac{t_{2}}{\boldsymbol{t}_{1}}, \quad \boldsymbol{t}_{1}, \boldsymbol{t}_{2}=$ material sample thickness before and after single rolling pass and

$\theta=$ apparent shear angle. The equation (6) for effective plastic strain consists of two strain components i.e. shear strain and normal strain. It shows that the induced strain depends on final to initial roll thickness ratio $r$, apparent shear angle $\theta$ (angle at a given position with respect to the perpendicular to the surface of the sheet before rolling) and the number of passes N. Other factors such as roll speed ratio (upper roller to lower roller speed ratio), rolling force and temperature also determine mechanical and microstructures properties of processed material [53].

Successful use of AR method to produce ultrafine grain and high strength biomedical titanium alloys have been reported in the literature. Kim et al. [54] showed that CP-Ti processed with AR at 1 -pass, 3-speed ratio and 63\% thickness ratio achieved ultra- fine grain size of $100 \mathrm{~nm}-300 \mathrm{~nm}$, an increase of tensile strength by $100 \%$ (up to 915 $\mathrm{MPa}$ ) compared to coarse grain one. Results showed that AR is among competitive SPDs techniques like HPT, ECAP and ARB. Chao et al. [55] worked on a comparison of AR and SR based on microstructure and texture evolution of Ti-6Al-4V alloy. Due to a higher level of effective strain and continuous rotation of the principle axis, asymmetric rolling resulted in a greater extent of grain refinement (equiaxed grains with mean size of $180 \mathrm{~nm}$ ) compared with symmetric rolling. The basal texture component was displaced from the normal toward rolling direction during asymmetric rolling, differing from the symmetric rolling textures.

A series combination of AR with other SPD processes on titanium alloys has given better grain refinement and strength than that achieved by AR alone. Li et al. [56] combined asymmetric 
rolling (AR) (at 15 passes, 83\%) and symmetric rolling (SR) (at 4 passes, $80 \%$ ) processes on CPTi grade 2 at room temperature. Results showed that after AR; grain size was $130 \mathrm{~nm}$, tensile and yield strengths increased from 363 and $470 \mathrm{MPa}$ to 652 and $780 \mathrm{MPa}$ respectively. After combined $(\mathrm{AR}+\mathrm{SR})$; grain size was $80 \mathrm{~nm}$, tensile strength increased from $470 \mathrm{MPa}$ (coarse grain) to 920 $\mathrm{MPa}$. The ductility reduced from $25.5 \%$ to $6.5 \%$. Micro hardness of nano grain material increased by $70 \%$ compared to coarse grain one. Vickers Hardness anisotropy was observed in samples direction axes (Figure 5) as; $\mathrm{HV}_{(\mathrm{RD}-\mathrm{TD})}>\mathrm{HV}_{(\mathrm{RD}-}$ ND) $>\mathrm{HV}_{\text {(TD-ND). }}$ The ultimate strength achieved was contributed by nano grain formation and high dislocations density accumulated in the samples. AR is an effective SPD technique to process biomedical titanium alloys with enhanced properties such as ultra-fine/nano grain structure, strength and homogeneous strain distribution.

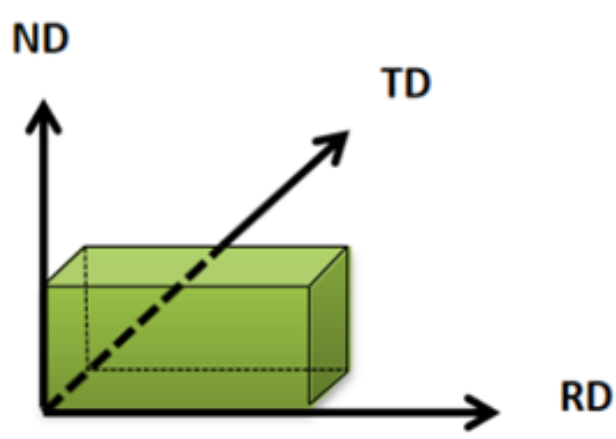

Figure 5: A rolled sheet sample represented in roll $(R D)$, normal (ND) and transverse (TD) directions.

The process involves repeating of rolling passes. It can be easily implemented on modified conventional rolling equipment. The process is applicable but limited to continuous and mass production of rectangular sheets. However, AR processed samples have shown changes of sample geometrical dimensions and reduction of ductility properties.

\subsection{Accumulative Roll Bonding (ARB)}

ARB is the SPD process performed on sheet materials using a conventional rolling machine. The principle of ARB is represented in Figure 6. First a sheet sample is surface cleaned, rolled then cut into two pieces, the two pieces are surface cleaned and brushed (to remove oxides and other contaminants), stacked and rolled again. The process can be repeated for infinity number of cycles where large plastic strains can be achieved. Induced shear strain in a rolled sample per pass is calculated using equation (7) [57] as:

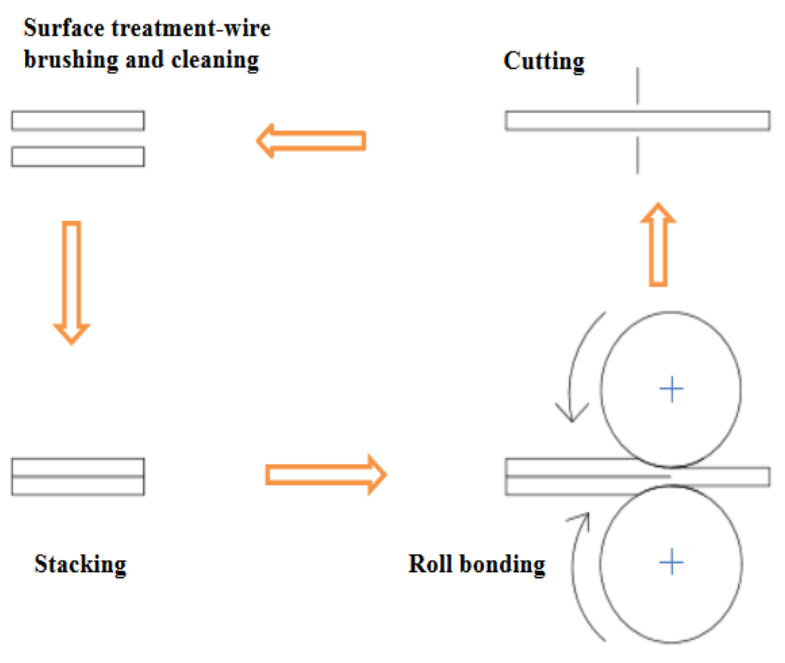

Figure 6: Principle of ARB process

$\boldsymbol{\varepsilon}_{\text {eff }}=N \frac{2}{\sqrt{3}} \ln \left(\frac{\boldsymbol{t}_{1}}{\boldsymbol{t}_{2}}\right)$

$\mathrm{t}_{1}$ and $\mathrm{t}_{2}=$ initial and after rolling thicknesses of sample respectively and $\mathrm{N}=$ number of passes. The magnitude of shear strain is dependent on the thickness reduction ratio (initial to final thickness ratio, $r$ ) and the number of passes $\mathrm{N}$. Other factors for induced strain include; degree of surface treatment, rolling force, rollers' diameters and speed and the working temperature. A deformation ratio of $35 \%-50 \%$ is recommended in each cycle [52][57]. Strong bonding of processed sheets is achieved by the proper surface treatment (cleaning, degreasing and wire brushing) of cut samples prior to stacking. For better bonding and workability, it is recommended the ARB process be performed at elevated temperature below material recrystallization temperature [58][59]. The main difference between ARB and conventional rolling is redundant shear strain imposed on material after the ARB process. ARB performs two functions simultaneously on the material; shear strain deformation and bonding of the stacked sheets. The number of ARB passes run is proportional to the magnitude of induced strain, smaller grain size, higher tensile strength and 
Mwita et al., J. Mod. Mater;; Vol. 5, Issue 1, pp: 8-23, 2018

hardness of the material. Various works in the literature have reported the use of $A R B$ to enhance biomedical titanium alloys with ultrafine grain and improved mechanical properties [6][12][60]. Du et al. [61] manufactured Ti-Al metal composites using hot pressing followed by multi pass hot rolling at $773 \mathrm{~K}$. Ti-Al laminated sheets showed strong bonding with intermetallic interface layers of nano scale thickness. Manufactured composites showed a good combination of strength and ductility and their tensile properties decreased with increase of AlTi thickness ratio.

Fattah-alhosseini et al. [12] investigated mechanical and microstructure properties of CPTi processed by ARB at room temperature for 6 passes. Results showed that as the number of passes increased, the grain size decreased from $45 \mu \mathrm{m}$ to $90 \mathrm{~nm}$, this was due to high angle grain boundaries and accumulation of dislocations. The grain refinement and strain hardening rate were remarkable during initial passes, afterwards they reached a saturation point. Fracture elongation decreased from 35\%-10\%. Micro hardness increased from $184 \mathrm{HV}$ to $370 \mathrm{HV}$. Also, there was improved hardness homogeneity that was indicated by the uniform distribution of hardness in the tested samples. The yield stress and tensile strength increased from $284 \mathrm{MPa}$ and $415 \mathrm{MPa}$ to $799 \mathrm{MPa}$ and $989 \mathrm{MPa}$ respectively. The ultrafine grained CP-Ti processed by ARB exhibited tensile strength relatively higher than $900 \mathrm{MPa}$ of $\mathrm{Ti} 6 \mathrm{Al} 4 \mathrm{v}$ with similar $10 \%$ elongation. Kitahara et al.[60] studied fatigue properties of CP-Ti processed with ARB for 6 passes. Deformed samples showed equiaxed grains and elongated lamellar grains of sizes $89 \mathrm{~nm}$ and $65 \mathrm{~nm}$ respectively. Increase of number of $\mathrm{ARB}$ to 6 passes increased the tensile strength by $100 \%$ to $850 \mathrm{MPa}$ and decreased the rate of fatigue crack propagation. Stress intensity factor decreased from $6.80 \mathrm{MPam}^{1 / 2}$ for as received samples to $2.20 \mathrm{MPam}^{1 / 2}$ for samples processed at 4 passes. The ductility decreased from $30 \%$ to $10 \%$ at 6 passes. ARB is an effective technique to enhance titanium biomedical alloys with improved properties such as ultrafine/nano grain structure, tensile and fatigue strength and hardness. This process can be easily performed on conventional rolling equipment that may be available in the workshop. However, ARB is also associated with loss of material ductility. Currently it is limited to process samples of rectangular cross section. Another serious drawback is the edge cracks and fracture of sheets of low ductile materials that may occur at higher cycles. Edge cracking is caused by large amount of total plastic strain accumulated in the material noting that the rolling is not a hydrostatic process. At that stage it is impossible to proceed to the next cycle. Repeated cutting, surface cleaning and stacking of laminate involves wastage of materials and poses a risk of surface and grains contamination that ultimately compromise interfacial layers bond strength. ARB has not yet been implemented for continuous and mass production.

\subsection{Repetitive Corrugation and Straightening (RCS)}

\subsubsection{The Principle of the RCS Process}

RCS is the process where plastic simple shear bending strain is induced in material via repeated corrugation (bending) and straightening (flattening). Therefore, in this process, deformation mode is mainly bending. Like HPT and ECAP processes, RCS induces plastic strain to the material sample without significantly changing its geometric dimensions. As a result ultra-fine grain is achieved in material with enhanced desired mechanical properties [62] [63]. RCS was developed by Huang et al. [64] to process ultra-fine grain structure $99 \%$ pure copper sheets with increased strength and hardness. In RCS, corrugation and straightening of material are performed with either a continuous or a discontinuous process tools. The continuous process consists of two pairs of rotating rollers (Figure 7a); one pair of rollers is for corrugation and the other for straightening. The discontinuous process consists of two pairs of pressing dies (Figure 7b); one pair of dies is for corrugation and the other for straightening. Different corrugating die surface profiles that have been reported in the literature include; Vgroove, Flat-groove and Semi-circular die [65][66][67]. Sketches of these dies are presented in Figure 8. 


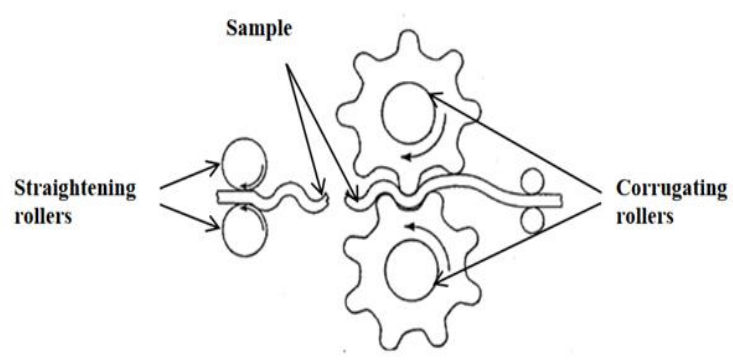

7(a)

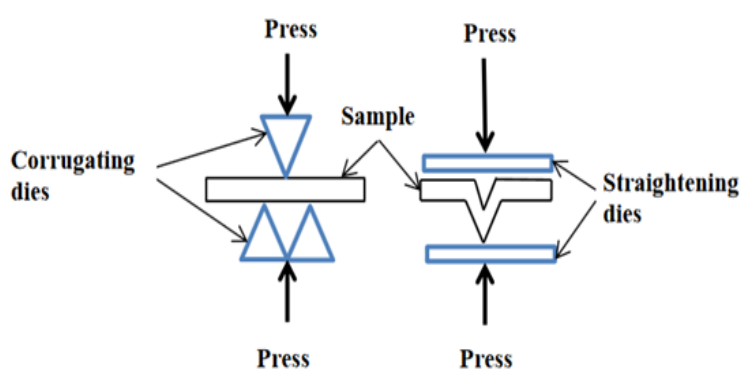

7(b)

Figure 7: Principle of RCS process (a) corrugating and straightening rollers (CSR) for a continuous process (b) groove pressing and straightening

(GPS) dies for a discontinuous process.

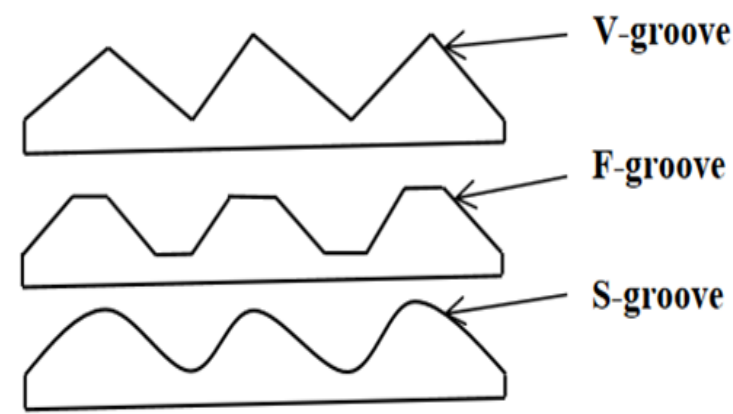

Figure 8: Vee (V)-groove, Flat (F)-groove and Semi-circular $(S)$ dies.

The effective strain for the RCS semi-circular die profile is given

by equation (8) [65] as:

$\mathcal{E}_{\text {eff }}=N \frac{4}{\sqrt{3}} \ln \left(\frac{r+t}{r+0.5 t}\right)$

$\mathrm{r}=$ radius of corrugating surface, $\mathrm{t}=$ thickness of sample and $\mathrm{N}=$ number of passes.

For Vee and Flat grooved dies, the effective strain is given in [65] as:

$\boldsymbol{\varepsilon}_{\text {eff }}=N \frac{\gamma}{\sqrt{3}}$ $\gamma=\gamma_{x y}=\frac{x}{t}$

$\mathrm{x}=$ the groove (tooth) height of the Flat or Veegrooved die

$\mathrm{t}=$ thickness of sample, $\gamma=$ engineering shear strain induced in material. The effective strain equations are also available in [68][69] works. Induced strain is dependent on the number of input factors, these are; die profile, die geometric dimensions, sheet sample thickness, number of passes performed and working temperature. Deformation or strain path mode also plays a significant role in performance of RCS process. On the other hand, induced strain mode (magnitude and homogeneity) determines RCS performance output factors such as; coarse to ultra-fine/nano grain refinement and improved mechanical properties (tensile strength, hardness, ductility).

\subsubsection{Deformation of Material and Strain Paths under RCS}

Deformation behavior of the material under RCS can be illustrated with a schematic diagram for a specimen and groove pressing (GP) (also known as a RCS discontinuous process) dies shown in Figure 9 .

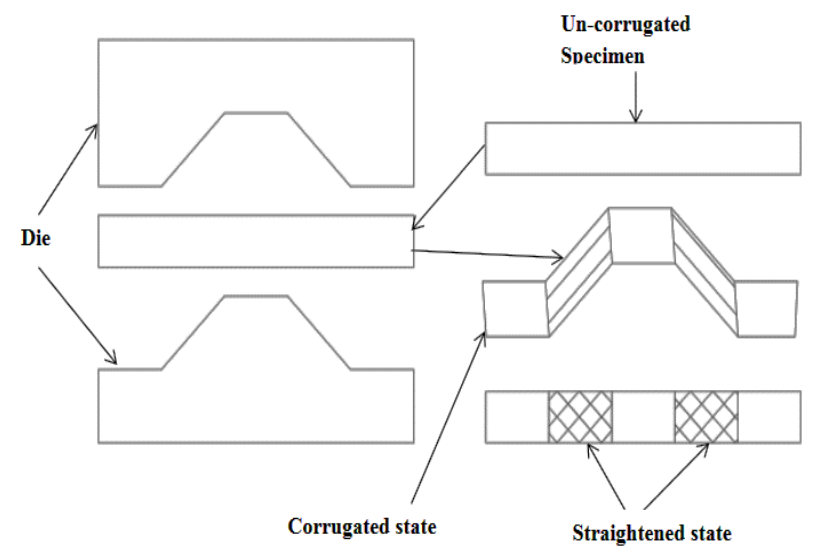

Figure 9: GP dies and deformation behavior induced in the material specimen.

A groove pressed specimen in three stage states (un-corrugated, corrugated and straightened) is presented. In the corrugated state, the inclined planes represented by the parallel lines are the most deformed/strained parts while the flat (horizontal) planes are the least or nondeformed/strained parts. During straightening 
Mwita et al., J. Mod. Mater;; Vol. 5, Issue 1, pp: 8-23, 2018

back to flat state, more strain is induced to the inclined planes while the horizontal planes remaining relatively un-deformed. After straightening process, still deformation variation (heterogeneity) remains in the material as shown with most deformed and least/non-deformed parts (indicated in crossed lines and plain surfaces respectively). The Von Mises equations (8) and (9) for effective strain induced in material for each RCS corrugation and straightening assume that deformation in material is homogeneous, but in reality, there is spatial deformation heterogeneity. Therefore, deformation variation will remain even if material is pressed and straightened for several passes and it results to strain, strength and hardness heterogeneity in the material sample. Various authors have reported on the use of RCS to enhance biomedical titanium alloys with refined grain structure and improved mechanical properties. Thirugnanam $e t$ al. [70] studied bioactivity of CP-Ti sheets processed by groove pressing (GP) up to 3 passes before cracks initiated at room temperature. Results showed that microstructure grain size decreased from $50 \mu \mathrm{m}$ as received material to $3 \mu \mathrm{m}$ with dominant twining spanning grains. Material yield strength increased from $325 \mathrm{MPa}$ to 432 $\mathrm{MPa}$ at 2 passes and elongation to fracture decreased by $85 \%$. Hardness increased from 125 $\mathrm{HV}$ for received material to a maximum of 203 $\mathrm{HV}$ at 2 passes. The GP processed CP-Ti sheets showed strain heterogeneity with good bioactivity for bone implant application. In an attempt to improve strain magnitude and homogeneity of GP process, constrained groove pressing (CGP) process was introduced. The schematic diagram for CGP using asymmetric die with the work piece is shown in Figure 10.

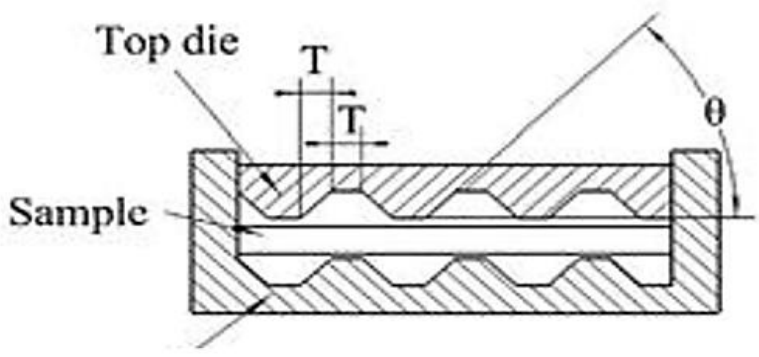

Bottom die

Figure 10: Constrained groove pressing $(C G P)$ die with groove size $T$ and angle $\theta$.
In CGP, material sample ends are constrained from expansion during pressing and flattening hence increasing accumulative strain without significantly changing its macroscopic dimensions. Kumar et al. [68] reported on grain refinement properties of CP-Ti sheets processed by CGP at $300^{\circ} \mathrm{C}$ temperature up to 8 passes. Results showed an improvement in tensile strength, hardness and grain refinement from; $323 \mathrm{MPa}-466 \mathrm{MPa}, 125 \mathrm{HV}-208 \mathrm{HV}$ and $40 \mu \mathrm{m}-$ $500 \mathrm{~nm}$ respectively. Ductility of material decreased by $66.6 \%$ and elongated grains were dominant in the microstructure. Constrained groove pressing-cross rotation (CGP-CR is an improved version of CGP adopted to improve strain and strength homogeneity in material. A schematic diagram for the CGP-CR process stages is presented in Figure 11. In a one CGP$\mathrm{CR}$ process pass, firstly, the work piece is performed bending and straightening. Secondly, it is rotated $180^{\circ}$ about the vertical normal axis then performed bending and straightening. Thirdly the work piece is rotated $90^{\circ}$ about the vertical normal axis performed bending and straightening. Fourthly, it is rotated $180^{\circ}$ about the vertical normal axis and performed bending and straightening. Afterwards the workpiece is rotated $90^{\circ}$ about the vertical normal axis. The process can be repeated for several passes.

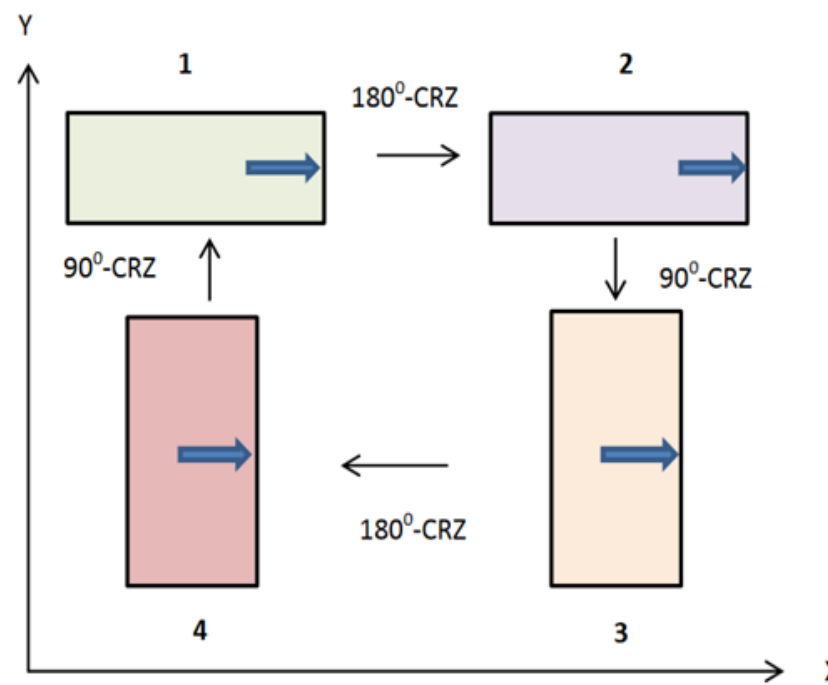

Figure 11: One pass of CGP-CR process with 1-4 stages of corrugation and straightening. Thicker arrows and $C R Z$ represents the sample rolling direction and clockwise rotation about $Z$-axis normal to $X-Y$ plane respectively. 
Performance and Prospects of Severe Plastic Deformation for Effective Biomedical Titanium Alloys

Khodabakhshi et al. [71] did experimental and 3D simulation on low carbon steel sheets processed by CGP-CR at 2 passes and found that tensile strength and hardness increased from 218 $\mathrm{MPa}-426 \mathrm{MPa}$ and $97 \mathrm{HV}-176 \mathrm{HV}$ respectively. Grain refinement from $30 \mu \mathrm{m}$ to $250 \mathrm{~nm}$ was achieved. It was concluded that the CGP-CR method performed better than CGP and GP processes. Moradpour et al.[63] used CGP-CR to study microstructure and mechanical properties of AA5052 alloy at room temperature. Deformed samples showed grain size of $300 \mathrm{~nm}-500 \mathrm{~nm}$, the rise of dislocation density increased hardness and tensile strength by $75 \%$ and $105 \%$ respectively. CGP-CR deformed samples hard better isotropic hardness homogeneity than annealed ones.

\subsubsection{Effect of Die Profile on Properties of RCS Processed Samples}

The profile of pressing die has an impact on the RCS induced strain, ductility, strength and other material properties. Thangapandian et al.[65] experimented on the effects of semicircular ( $\mathrm{r}$ $=5 \mathrm{~mm})$, flat-groove $(\mathrm{x}=5 \mathrm{~mm})$ and V-groove $(\mathrm{x}$ $=10 \mathrm{~mm}$ : refer to equations 8 and 9) dies on tensile, ductility, hardness and microstructure properties of GP processed Al-Mg alloy sheets, $3 \mathrm{~mm}$ thick. Results showed that; a semicircular die withstood 15 passes (highest number) without cracking. Samples showed good strain homogeneity and the best ductility (ductility reduction of $31 \%$ ), improved strength (from $60 \mathrm{MPa}-173 \mathrm{MPa}$ at 6 passes) and had the least hardness values than other dies. Improved grain refinement was from $45 \mu \mathrm{m}$ of received material to $20 \mu \mathrm{m}$. Flat-groove die pressed samples withstood 8 passes without cracking, with lowest ductility (ductility reduction of $66 \%$ ), had the least strain homogeneity, maximum strength (from $60 \mathrm{MPa}-175 \mathrm{MPa}$ at 6 passes) with average hardness compared to $\mathrm{V}$-groove and semicircular dies. Grain refinement was improved from $40 \mu \mathrm{m}$ of received material to $28 \mu \mathrm{m}$. V-groove die pressed samples withstood 4 passes without cracking, with ductility reduction of $63 \%$. The samples showed highest strain homogeneity and refined grains from $40 \mu \mathrm{m}$ of received material to $22 \mu \mathrm{m}$. Improved strength (from $60 \mathrm{MPa}-170 \mathrm{MPa}$ at 2 passes) was achieved. Hardness values of Vgroove pressed samples were slightly higher than that of flat-groove and semicircular dies pressed samples. However, the sharpness of a V-groove die imparts damage and stress concentrations to the material. Based on these results, it was concluded that a semicircular die profile is preferred for optimal strain homogeneity, high ductility, low possibility of cracks formation, grain refinement and improved strength.

\subsubsection{Die Sizes and their Applicability to Process Bulky Sheets}

Current RCS corrugating dies in use are of limited size. The dies' sizes reported in the literature are less than $200 \mathrm{~mm} \times 50 \mathrm{~mm}$ (length $\mathrm{x}$ width) respectively[64][68][72]. Hence these processes have not yet been applied at the industrial scale for manufacturing of ultra-fine large size biomedical titanium sheets. However, large size dies may need advanced technology and will have economic implication in terms of operating forces, associated drive systems, die material and machining costs.

RCS and its related methods (GP, CGP and CGP-CR) are potential effective techniques to produce biomedical titanium alloys with enhanced functional properties without significant change in geometrical dimensions. Although a little literature is available on application of RCS processes on biomedical titanium alloys, still the techniques have the potential of being implemented for continuous bulky production of ultra-fine biomedical titanium sheets. A serious challenge to these methods is deformation/strain heterogeneity induced in the samples. This is due to uneven deformation (strain paths) in the material during corrugation and straightening. At higher deformation passes, material losses ductility and results to formation of cracks and fracture. Compared to other SPD methods, performance of RCS on grain refine and strengthening of titanium alloys is lower. Biomedical titanium processed with GP and CGP methods have been reported to achieve the highest increase of strength below $40 \%[68][70]$, this value is lower compared to about $100 \%$ increase in strength by using HPT, ECAP and ARB methods. There is a 
need for improved design of RCS that considers efficiency, induced deformation/strain homogeneity and continuous manufacturing of ultra-fine, high strength and large size biomedical titanium sheets.

\section{Conclusions}

An extensive work reported in the literature shows that HPT, ECAP, AR, ARB and RCS SPD methods are effective to process ultra-fine/nano titanium alloys with enhanced properties (strength, biocompatibility, corrosion and wear resistance) for biomedical applications. However, HPT and ECAP are more effective than other methods due to their real hydrostatic stress state with insignificant change of sample geometric dimensions. Successful application of SPD to process biomedical titanium alloys are at experimental scale and face a number of challenges that need to be worked on. SPD processes need massive operating forces hence they are still experimented on small size samples and tools, most of the processes require several cycles of discrete operations to achieve material desired properties. SPD processed materials significantly lose ductility with increasing number of deformation passes. Processed materials exhibit strain (deformation) heterogeneity due to un-even distribution of strain paths during deformation, significant strain heterogeneity has been observed in HPT and RCS processed samples. The above-mentioned challenges are hindering adaptation of SPD from laboratory scale to the industrial scale for bulk and continuous production of biomedical titanium alloys. However, AR, ARB and RCS processes are viable for future implementation at industrial scale-mass production due to their simplicity and the rolling facility required. Improved SPD processes for continuous production have been reported, these includes Continuous-HPT, ECAP-Conform and Incremental-ECAP. Future research should pay attention to processes, tools and equipment that are both efficient and economical for SPD to process continuously large size biomedical titanium alloys with homogeneous properties.

\section{Acknowledgment}

The authors are grateful to the University of Johannesburg for funding this research study through the Global Excellent Statue (GES-2017) Scholarship.

\section{How to Cite this Article:}

W. Mwita, E. Akinlabi, and K. Sanusi, "Performance and Prospects of Severe Plastic Deformation for Effective Biomedical Titanium Alloys", J. Mod. Mater., vol. 5, no. 1, pp. 8-23, Feb. 2018. doi: 10.21467/jmm.5.1.8-23

\section{References}

[1] A. V. Polyakov, I. P. Semenova, and R. Z. Valiev, "High fatigue strength and enhanced biocompatibility of UFG CP Ti for medical innovative applications," IOP Conf. Ser. Mater. Sci. Eng., vol. 63, pp. 1-6, Aug. 2014.

[2] G. Lütjering and J. C. Williams, Titanium : Engineering Materials and Processes, Second Edi. New York: Springer Berlin Heidelberg, 2007.

[3] D. J. Fernandes, C. N. Elias, and R. Z. Valiev, "Properties and Performance of Ultrafine Grained Titanium for Biomedical Applications," Mater. Res., vol. 18, no. 6, pp. 1163-1175, Nov. 2015.

[4] M. Niinomi, Y. Liu, M. Nakai, H. Liu, and H. Li, "Biomedical titanium alloys with Young's moduli close to that of cortical bone," Regen. Biomater., vol. 3, no. 3, pp. 173-185, Sep. 2016.

[5] C. Oldani and A. Dominguez, "Titanium as a Biomaterial for Implants," in Recent Advances in Arthroplasty, S. K. Fokter, Ed. InTechOpen, 2012, pp. 150-162.

[6] H. Hermawan, D. Ramdan, and J. Djuansjah, "Metals for Biomedical Applications," in Biomedical Engineering from Theory to Applications, R. Fazel, Ed. InTechOpen, 2011, pp. 412-440.

[7] M. Niinomi, "Fatigue performance and cyto-toxicity of low rigidity titanium alloy, Ti-29Nb-13Ta-4.6Zr," Biomaterials, vol. 24, no. 16, pp. 2673-2683, Jul. 2003.

[8] X. Zhao, Y. Xirong, X. Liu, C. Wang, Y. Huang, and T. G. Langdon, "Processing of commercial purity titanium by ECAP using a 90 degrees die at room temperature," Mater. Sci. Eng. A, vol. 607, pp. 482489, Jun. 2014.

[9] S. J. Li, M. Niinomi, T. Akahori, T. Kasuga, R. Yang, and Y. L. Hao, "Fatigue characteristics of bioactive glass-ceramic-coated Ti-29Nb-13Ta-4.6Zr for biomedical application," Biomaterials, vol. 25, no. 17, pp. 3369-3378, Sep. 2004.

[10] C. N. Elias, M. A. Meyers, R. Z. Valiev, and S. N. Monteiro, "Ultrafine grained titanium for biomedical applications: An overview of performance," J. Mater. Res. Technol., vol. 2, no. 4, pp. 340-350, Nov. 2013.

[11] Y. Kirmanidou et al., "New Ti-Alloys and Surface Modifications to Improve the Mechanical Properties and the Biological Response to Orthopedic and Dental Implants: A Review," Biomed Res. Int., vol. 2016, pp. 1-22, Jan. 2016.

[12] A. Fattah-alhosseini, A. Reza, Y. Mazaheri, and M. Karimi, "An Investigation of mechanical properties in 
accumulative roll bonded nano-grained pure titanium," Mater. Sci. Eng. A, vol. 688, pp. 218-224, Mar. 2017.

[13] X. Zhang and H. Sehitoglu, "Crystallography of the $\mathrm{B} 2 \rightarrow \mathrm{R} \rightarrow \mathrm{B} 19^{\prime}$ phase transformations in NiTi," Mater. Sci. Eng. A, vol. 374, pp. 292-302, Jun. 2004.

[14] L. Petrini and F. Migliavacca, "Biomedical Applications of Shape Memory Alloys," J. Metall., vol. 2011, pp. 1-15, Jun. 2011.

[15] J. Il Kim, H. Y. Kim, H. Hosoda, and S. Miyazaki, "Shape Memory Behavior of $\mathrm{Ti}-22 \mathrm{Nb}-(0.5-2$. 0 ) O ( at $\{\%\})$ Biomedical Alloys," Mater. Trans., vol. 46, no. 4, pp. 852-857, Apr. 2005.

[16] L. Mishnaevsky et al., "Nanostructured titaniumbased materials for medical implants: Modeling and development," Mater. Sci. Eng. R Reports, vol. 81, no. 1, pp. 1-19, Jul. 2014

[17] M. T. Mohammed, "Mechanical and wear properties of HPT-biomedical titanium: A review," Biomater. Biomech. Bioeng., vol. 2, no. 3, pp. 185-196, Nov. 2015.

[18] S. Bagherifard, R. Ghelichi, A. Khademhosseini, and M. Guagliano, "Cell response to nanocrystallized metallic substrates obtained through severe plastic deformation," ACS Appl. Mater. Interfaces, vol. 6, no. 11, pp. 7963-7985, Apr. 2014

[19] M. Krystian, K. Bryła, J. Horky, and B. Mingler, "Equal Channel Angular Pressing (ECAP) of hollow profiles made of titanium," IOP Conf. Ser. Mater. Sci. Eng., vol. 194, no. 1, pp. 1-6, Jul. 2017.

[20] M. Niinomi, "Enhancement of mechanical biocompatibility of titanium alloys by deformationinduced transformation," Mater. Sci. Forum, vol. 879, pp. 125-130, 2017.

[21] R. Z. Valiev, R. K. Islamgaliev, and I. V. Alexandrov, "Bulk nanostructured materials from severe plastic deformation," Prog. Mater. Sci., vol. 45, no. 2, pp. 103-189, Jan. 2000.

[22] Y. Estrin and A. Vinogradov, "Extreme grain refinement by severe plastic deformation: A wealth of challenging science," Acta Mater., vol. 61, no. 3, pp. 782-817, Feb. 2013.

[23] C. T. Wang, N. Gao, M. G. Gee, R. J. K. Wood, and T. G. Langdon, "Tribology testing of ultrafine-grained Ti processed by high-pressure torsion with subsequent coating," J. Mater. Sci., vol. 48, no. 13, pp. $4742-$ 4748, Jul. 2013.

[24] H. Shahmir, M. Nili-Ahmadabadi, Y. Huang, and T. G. Langdon, "Evolution of microstructure and hardness in NiTi shape memory alloys processed by high-pressure torsion," J. Mater. Sci., vol. 49, no. 8, pp. 2998-3009, Jan. 2014.

[25] N. Lugo, N. Llorca, J. M. Cabrera, and Z. Horita, "Microstructures and mechanical properties of pure copper deformed severely by equal-channel angular pressing and high pressure torsion," Mater. Sci. Eng. A, vol. 477, no. 1-2, pp. 366-371, Mar. 2008.

[26] M. T. M. Shahir Hussain, "Mechanical Properties of ECAP-Biomedical Titanium Materials: A Review," Int. J. Innov. Res. Sci. Eng. Technol., vol. 4, no. 5, pp. 2700-2704, May 2015.

[27] Y. Todaka, M. Umemoto, A. Yamazaki, J. Sasaki, and K. Tsuchiya, "Effect of Strain Path in High-Pressure Torsion Process on Hardening in Commercial Purity Titanium," Mater. Trans., vol. 49, no. 1, pp. 47-53, Dec. 2008.
[28] M. Nakai, M. Niinomi, J. Hieda, H. Yilmazer, and Y. Todaka, "Heterogeneous grain refinement of biomedical Ti-29Nb-13Ta-4.6Zr alloy through highpressure torsion," Sci. Iran., vol. 20, no. 3, pp. 10671070, 2013.

[29] M. Farvizi, M. R. Akbarpour, E. Y. Yoon, and H. S. Kim, "Effect of high-pressure torsion on the microstructure and wear behavior of NiTi alloy," Met. Mater. Int., vol. 21, no. 5, pp. 891-896, 2015.

[30] K. Edalati, S. Lee, and Z. Horita, "Continuous highpressure torsion using wires," J. Mater. Sci., vol. 47, no. 1, pp. 473-478, Jan. 2012.

[31] Y. Huang, S. Mortier, P. H. R. Pereira, P. Bazarnik, M. Lewandowska, and T. G. Langdon, "Thermal stability and mechanical properties of HPT-processed CP-Ti," IOP Conf. Ser. Mater. Sci. Eng., vol. 194, pp. 1-6, May 2017.

[32] M. Ashida, P. Chen, H. Doi, Y. Tsutsumi, T. Hanawa, and Z. Horita, "Microstructures and mechanical properties of Ti-6Al-7Nb processed by high-pressure torsion," Procedia Eng., vol. 81, no. October, pp. 1523-1528, Oct. 2014.

[33] B. Z. Jiang, S. Emura, and K. Tsuchiya, "Microstructures and mechanical properties of Ti5553 alloy processed by high-pressure torsion," IOP Conf. Ser. Mater. Sci. Eng., vol. 63, no. 1, pp. 1-8, Aug. 2014.

[34] K. Sharman et al., "Enhancement in mechanical properties of a $\beta$-titanium alloy by high-pressure torsion," J. Mater. Res. Technol., vol. 4, no. 1, pp. 7983, Nov. 2015.

[35] M. Nie, C. T. Wang, M. Qu, N. Gao, J. A. Wharton, and T. G. Langdon, "The corrosion behaviour of commercial purity titanium processed by highpressure torsion," J. Mater. Sci., vol. 49, no. 7, pp. 2824-2831, Apr. 2014.

[36] C. T. Wang, A. G. Fox, and T. G. Langdon, “An Investigation of Hardness Homogeneity and Microstructure in Pure Titanium Processed by High Pressure Torsion," Mater. Sci. Forum, vol. 783-786, pp. 2701-2706, May 2014.

[37] H. Shahmir, M. Nili-Ahmadabadi, Y. Huang, J. Myun Jung, H. Seop Kim, and T. G. Langdon, "Shape memory effect in nanocrystalline NiTi alloy processed by high-pressure torsion," Mater. Sci. Eng. A, vol. 626, pp. 203-206, Feb. 2015.

[38] A. Hohenwarter, "Incremental high pressure torsion as a novel severe plastic deformation process: Processing features and application to copper," Mater. Sci. Eng. A, vol. 626, pp. 80-85, Mar. 2015.

[39] V. M. Segal, "Materials processing by simple shear," Mater. Sci. Eng. A, vol. 197, no. 1995, pp. 157-164, Jul. 1995.

[40] F. Djavanroodi, B. Omranpour, M. Ebrahimi, and M. Sedighi, "Designing of ECAP parameters based on strain distribution uniformity," Prog. Nat. Sci. Mater. Int., vol. 22, no. 5, pp. 452-460, Oct. 2012.

[41] Y. Gu, A. Ma, J. Jiang, Y. Yuan, and H. Li, "Deformation structure and mechanical properties of pure titanium produced by rotary-die equal-channel angular pressing," Metals (Basel)., vol. 7, no. 297, pp. 1-10, Aug. 2017.

[42] K. Ivanov, "Comparative TEM study of microstructures of $\mathrm{Ti}-6 \mathrm{Al}-4 \mathrm{~V}$ alloy processed by equal channel angular pressing and helical plus groove rolling," Int. Conf. Adv. Mater. with 
Mwita et al., J. Mod. Mater.; Vol. 5, Issue 1, pp: 8-23, 2018

Hierarchical Struct. New Technol. Reliab. Struct., vol. 1783, Nov. 2016.

[43] M. Gzyl, A. Rosochowski, S. Boczkal, L. Olejnik, and M. N. Katimon, "Producing High-Strength Metals by I-ECAP," Adv. Eng. Mater., vol. 18, no. 2, pp. 219223, May 2016.

[44] E. Prokofyev, D. Gunderov, S. Prokoshkin, and R. Valiev, "Microstructure, mechanical and functional properties of NiTi alloys processed by ECAP technique," ESOMAT 2009 - 8th Eur. Symp. Martensitic Transform., vol. 6028, pp. 0-4, Sep. 2009.

[45] D. T. Zhang et al., "Effect of annealing temperature on martensitic transformation of Ti49.2Ni50.8alloy processed by equal channel angular pressing," Trans. Nonferrous Met. Soc. China (English Ed., vol. 26, no. 2, pp. 448-455, Feb. 2016.

[46] B. Kockar, I. Karaman, J. I. Kim, and Y. Chumlyakov, "A method to enhance cyclic reversibility of NiTiHf high temperature shape memory alloys," Scr. Mater., vol. 54, no. 12, pp. 2203-2208, Jun. 2006.

[47] H. Shahmir, M. Nili-Ahmadabadi, and T. G. Langdon, "Shape memory effect of NiTi alloy processed by equal-channel angular pressing followed by post deformation annealing," IOP Conf. Ser. Mater. Sci. Eng., vol. 63, no. 1, pp. 1-9, 2014.

[48] M. J. Qarni, G. Sivaswamy, A. Rosochowski, and S. Boczkal, "Effect of incremental equal channel angular pressing (I-ECAP) on the microstructural characteristics and mechanical behaviour of commercially pure titanium," Mater. Des., vol. 122, pp. 385-402, May 2017.

[49] A. A. Mendes Filho, C. A. Rovere, S. E. Kuri, V. L. Sordi, and M. Ferrante, "A general study of commercially pure $\mathrm{Ti}$ subjected to severe plastic deformation: Microstructure, strength and corrosion resistance," Rev. Mater., vol. 15, no. 2, pp. 254-259, 2010.

[50] W. Polkowski, "Differential Speed Rolling: A New Method for a Fabrication of Metallic Sheets with Enhanced Mechanical Properties," in Progress in Metallic Alloys, V. Glebovsky, Ed. InTechOpen, 2016, pp. 111-126.

[51] R. Roumina and C. W. Sinclair, "Deformation geometry and through-thickness strain gradients in asymmetric rolling," Metall. Mater. Trans. A Phys. Metall. Mater. Sci., vol. 39, no. 10, pp. 1-9, Oct. 2008.

[52] B. Hai, L. Yu, C. Lu, A. K. Tieu, H. J. Li, and A. Godbole, "Special Rolling Techniques for Improvement of Mechanical Properties of Ultra fineGrained Metal Sheets : a Review," Adv. Eng. Mater., vol. 18, no. 5, pp. 754-769, May 2016.

[53] D. Tang, X. Liu, M. Song, and H. Yu, "Experimental and Theoretical Study on Minimum Achievable Foil Thickness during Asymmetric Rolling," PLoS One, vol. 9, no. 9, Sep. 2014.

[54] W. J. Kim, S. J. Yoo, and J. B. Lee, "Microstructure and mechanical properties of pure Ti processed by high-ratio differential speed rolling at room temperature," Scr. Mater., vol. 62, no. 7, pp. 451-454, Apr. 2010.

[55] Q. Chao, P. D. Hodgson, and H. Beladi, "Microstructure and Texture Evolution During Symmetric and Asymmetric Rolling of Martensitic Ti-6Al-4V alloy.," Metall. Mater. Trans. A, vol. 47, no. 1, pp. 531-545, Jan. 2016.

[56] Z. Li, A. Shan, and J. Jiang, "Improved Mechanical
Properties of Nano-grained $\mathrm{Ti}$ Processed by Combination of Asymmetric and Symmetric Rolling.," in Shanghai International Nanotechnology Cooperation Symposium, 2012, pp. 146-150.

[57] N. Tsuji, Y. Saito, S. H. Lee, and Y. Minamino, "ARB (accumulative roll-bonding) and other new techniques to produce bulk ultrafine grained materials," $A d v$. Eng. Mater., vol. 5, no. 5, pp. 338-344, Feb. 2003.

[58] N. Tsuji, Y. Saito, H. Utsunomiya, and S. Tanigawa, "Ultra-fine grained bulk steel produced by accumulative roll-bonding (ARB) process," Scr. Mater., vol. 40, no. 7, pp. 795-800, Mar. 1999.

[59] H. Sheikh and E. Paimozd, "Effect of Hot Accumulative Roll Bonding Process on the Mechanical Properties of AA5083," Open J. Met., vol. 1, pp. 12-15, Sep. 2011.

[60] H. Kitahara et al., "Fatigue Crack Propagation Behavior in Commercial Purity Ti Severely Deformed by Accumulative Roll Bonding Process," Mater. Trans., vol. 49, no. 1, pp. 64-68, Jan. 2008.

[61] G. Fan, Y. Du, T. Yu, N. Hansen, L. Geng, and X. Huang, "Laminated Ti-Al composites: Processing, structure and strength," Mater. Sci. Eng. A, vol. 673, pp. 572-580, Jul. 2016.

[62] P. M. Bhovi and K. Venkateswarlu, "Influence of $\mathrm{RCS}$ on $\mathrm{Al}-3 \mathrm{Mg}$ and $\mathrm{Al}-3 \mathrm{Mg}-0.25 \mathrm{Sc}$ alloys," IOP Conf. Ser. Mater. Sci. Eng., vol. 114, no. 1, pp. 1-7, 2016.

[63] M. Moradpour, F. Khodabakhshi, and H. Eskandari, "Microstructure-mechanical property relationship in an $\mathrm{Al}-\mathrm{Mg}$ alloy processed by constrained groove pressing-cross route," Mater. Sci. Technol., pp. 1-15, Jan. 2018.

[64] J. Huang, Y. Zhu, D. Alexander, X. Liao, T. Lowe, and R. Asaro, "Development of repetitive corrugation and straightening," Mater. Sci. Eng. A, vol. 371, no. 1, pp. 35-35, Apr. 2004.

[65] N. Thangapandian, S. Balasivanandha Prabu, and K. A. Padmanabhan, "Effects of die profile on grain refinement in Al-Mg alloy processed by repetitive corrugation and straightening," Mater. Sci. Eng. A, vol. 649, pp. 229-238, Sep. 2016.

[66] M. S. Ghazani and A. Vajd, "Finite Element Analysis of the Groove Pressing of Aluminum Alloy," Model. Numer. Simul. Mater. Sci., vol. 4, pp. 32-36, Jan. 2014.

[67] D. H. Shin, J. J. Park, Y. S. Kim, and K. T. Park, "Constrained groove pressing and its application to grain refinement of aluminum," Mater. Sci. Eng. A, vol. 328, no. 1, pp. 98-103, May 2002.

[68] G. V. P. Kumar, G. G. Niranjan, and U. Chakkingal, "Grain Refinement in Commercial Purity Titanium Sheets by Constrained Groove Pressing," Mater. Sci. Forum, vol. 683, pp. 233-242, May 2011.

[69] S. Fong, A. Danno, M. J. Tan, and B. Wah Chua, "Effect of Deformation and Temperature Paths in Severe Plastic Deformation Using Groove Pressing on Microstructure, Texture, and Mechanical Properties of AZ31-O," J. Manuf. Sci. Eng., vol. 137, no. 5, pp. 16-26, Feb. 2015.

[70] A. Thirugnanam, T. S. Sampath Kumar, and U. Chakkingal, "Tailoring the bioactivity of commercially pure titanium by grain refinement using 
groove pressing," Mater. Sci. Eng. C, vol. 30, no. 1, pp. 203-208, 2010.

[71] F. Khodabakhshi, M. Abbaszadeh, S. R. Mohebpour, and $\mathrm{H}$. Eskandari, "3D finite element analysis and experimental validation of constrained groove pressing-cross route as an SPD process for sheet form metals," Int. J. Adv. Manuf. Technol., vol. 73, no. 912, pp. 1291-1305, May 2014.

[72] N. Thangapandian and S. B. Prabu, "The Role of Corrugation Die Parameters on the Mechanical Properties of Aluminum Alloy (AA 5083) Processed by Repetitive Corrugation and Straightening," $J$. Mater. Sci. Chem. Eng., vol. 3, no. 7, pp. 208-212, 2015.
Publish your research article in AIJR journals-

$\checkmark$ Online Submission and Tracking

$\checkmark$ Peer-Reviewed

$\checkmark$ Rapid decision

$\checkmark$ Immediate Publication after acceptance

$\checkmark \quad$ Articles freely available online

$\checkmark \quad$ Retain full copyright of your article.

Submit your article at journals.aijr.in

Publish your books with AIJR publisher-

$\checkmark$ Publish with ISBN and DOI.

$\checkmark$ Publish Thesis/Dissertation as Monograph.

$\checkmark$ Publish Book Monograph.

$\checkmark$ Publish Edited Volume/ Book.

$\checkmark$ Publish Conference Proceedings

Retain full copyright of your books.

Submit your manuscript at books.aijr.org 